\title{
EDITORIAL
}

\section{Coming together: the ATS/ERS consensus on clinical pulmonary function testing}

\author{
V. Brusasco*, R. Crapo" and G. Viegi ${ }^{*}$
}

(O) ince 1979, guidelines for standardising pulmonary function tests have been published and updated by both the American Thoracic Society (ATS) [1-6] and the European Respiratory Society (ERS) [7-9]. In addition, several joint ATS/ERS workshops on pulmonary function testing have been held and the resulting reports published [10, 11]. In 1995, European scientists participated in the ATS updates of standards for spirometry and single-breath carbon monoxide diffusing capacity of the lung (DL,CO), but no joint statement has been published by the two societies. Although generally concordant, the spirometry and DL,CO guidelines published separately by the ATS and the ERS differed in some aspects that were of appreciable importance. Official guidelines for the measurement of lung volumes were made available by the ERS $[7,10]$, but not the ATS.

In recent years, global initiatives were undertaken for the diagnosis and treatment of pulmonary diseases, and the worldwide market for instruments to test lung function widened considerably. This increased the pressure for more uniform pulmonary function testing across the world, and prompted the ATS and the ERS to appoint a joint Task Force to provide new combined standards for clinical pulmonary function testing, with the hope that they will be accepted by other respiratory societies. A new Task Force on pulmonary function testing, implemented by the Forum of International Respiratory Societies (FIRS), has recently started its work based on the ATS/ERS documents.

Our Task Force consisted of 19 scientists with recognised expertise in pulmonary function testing. The group worked on a "one-draft" system, in which each of five sections was assigned to a small subgroup and eventually discussed by the whole committee. There was a general feeling that previous standards published by the two societies tended to be difficult to use because of their overwhelming details and the lack of a user-friendly indexing system. Therefore, one of the goals was a change in format, including a more comprehensive indexing system. We worked hard to make it easy for people to quickly find what they need.

From its beginning in 2001 (a "new millennium project") to the final approval in 2005, the Task Force met many times and had some tough negotiations, both face to face and by e-mail or

*Internal Medicine, University of Genoa, Genova, Italy. \#Pulmonary Division, LDS Hospital, Salt Lake City, UT, USA. "Institute of Clinical Physiology, National Research Council (CNR), Pisa, Italy.

CORRESPONDENCE: V. Brusasco, Internal Medicine, University of Genoa, Viale Benedetto XV, 6, Genova I-16132, Italy. Fax: 10 3537690. E-mail: vito.brusasco@unige.it conference call. We count it as one of our successes that all participants stayed in the process until reasonable solutions were found. As agreed, the new standards are due to appear as a series in five consecutive issues of the European Respiratory Journal, starting from the current one, which discusses general considerations for lung function testing [12].

The spirometry section [13], mainly drafted by M.R. Miller and J. Hankinson, is a model of clean user-friendly prose, which walks the reader through all the important elements of the test, from instrument to procedure quality control. One of the major steps forward is the recommendation that a standardised computer output format should be available on all instruments. This does not require equipment manufacturers to store their data in a specific format, but it does require them to provide a means of delivering the data in a standard way. This means that users won't be tied to a specific manufacturer in order to maintain their database structure. It also means that it will be relatively easy to write software to move spirometric data into healthcare databases where they can be used to monitor and guide therapy for patients with lung diseases. Such data can also be used for clinical research, including research into the efficacy of using pulmonary function tests in managing patients. Furthermore, International Organization for Standardization metrology terminology (www.iso.org) has been adopted.

The section on measurement of single-breath carbon monoxide uptake in the lung (i.e. DL,CO) [14], mainly drafted by N. MacIntyre, R. Crapo, G. Viegi, D.C. Johnson and C.P.M. van der Grinten, stirred up some controversy first in the drafting of the document and again in the comments received from reviewers. The areas of concern were primarily related to adjustments of $D \mathrm{~L}, \mathrm{CO}$ for lung volume (i.e. the use of $\mathrm{DL}, \mathrm{CO} /$ alveolar volume $(V \mathrm{~A})$ ) and how to interpret unadjusted and adjusted values if the decision was to adjust for lung volume. All agreed that the DL,CO relationship to $V \mathrm{~A}$ is complex, and that the simple $D \mathrm{~L}, \mathrm{CO} / V \mathrm{~A}$ value does not necessarily "correct" for a reduced $D \mathrm{~L}, \mathrm{CO}$ in the setting of a comparably reduced $V \mathrm{~A}$. There was also a significant discussion over how to deal with adjustments for haemoglobin and carboxyhaemoglobin concentrations. Upon recognition that adjustments for haemoglobin are under-utilised, we decided to adjust for these, but the adjustments need to be made to the predicted rather than the measured values. After the document was finalised, several committee members were informally polled to find out how they personally use $D \mathrm{~L}, \mathrm{CO} / V \mathrm{~A}$. The responses mirrored the review process. There was wide variation, ranging from "do not use it at all" and "do not print it on the report" to saying 
something about it on every interpretation. This variation amongst committee members suggests that more research on the clinical utility of $D \mathrm{~L}, \mathrm{CO} / \mathrm{VA}$ is required, to be possibly included in a future version. The decision to use the term $D \mathrm{~L}, \mathrm{CO}$ rather than the carbon monoxide transfer factor $(\mathrm{T} \mathrm{L}, \mathrm{CO})$ was not controversial until the document went for outside review. Everyone on the Task Force understood that TL,CO is more correct from a terminology and scientific standpoint, but perhaps it was the long history of $D \mathrm{~L}, \mathrm{CO}$ and its common usage that gave it the edge. Exercise and positional changes in $D \mathrm{~L}, \mathrm{CO}$ were not addressed, although it was recognised that they may provide an assessment of capillary recruitment and might, therefore, be useful clinically, and this may be another addition for a future version.

The lung volume section [15], mainly drafted by J. Wanger, J.L. Clausen, A. Coates and O.F. Pedersen, largely reflects a document that was produced after an international workshop held in 1990, funded by the National Heart Lung and Blood Institute (NHLBI). That document was very large and never published in full print, but those interested in all the details can find it posted on the ATS website [16]. In the new document, the relevant technical aspects and the limitations of the methods currently available for lung volume measurements are summarised in a user-friendly way. The position of lung volume measurements in the diagnosis of respiratory disorders and their cost-to-benefit ratio were probably the most controversial aspects of the Task Force.

The section on interpretative strategies [17], mainly drafted by R. Pellegrino, G. Viegi, P. Enright, V. Brusasco and R. Crapo, generated rather strong controversy, but only in a couple of areas. It emphasises the importance of selecting appropriate reference values and lower limits of the normal range, and provides a good listing of available reference studies with suggestions for dealing with ethnicity. Nevertheless, the committee realised that no single set of reference values can be recommended and more work will be necessary in this area. A detailed interpretative algorithm is presented, outlying the position of each test for a state-of-the-art diagnostic procedure in large hospital-based laboratories. Its use is not intended as mandatory and simpler assessments of pulmonary function are acceptable in different settings, keeping in mind the limitations that are inherent to simplicity. The assessment of reversibility of bronchoconstriction is covered in more detail than in previous documents, with reminders that a number of chronic obstructive pulmonary disease patients are more likely to respond with improvements of lung volumes than forced expiratory volume in one second.

As for any recommended standard, this one is not perfect, but reflects the current knowledge in the field. Therefore, it should be used as a guide for good clinical practice until changes are made based on new scientific evidence. A future goal would be the creation of standard pulmonary function reports, which present the relevant data in a format that enables an "easy interpretation and digestion of the information" [18].

\section{ACKNOWLEDGEMENTS}

On behalf of the whole group, we wish to thank E. Wouters (Maastricht, Netherlands) for the initial input to the project and B. Culver (Seattle, WA, USA) for the useful suggestions for revision. We are also indebted to P. Silvi (Pisa, Italy) and J. Embry (Salt Lake City, UT, USA) for editorial assistance.

\section{REFERENCES}

1 American Thoracic Society. Snowbird workshop on standardization of spirometry. Am Rev Respir Dis 1979; 119: 831-838.

2 American Thoracic Society. Standardization of Spirometry. 1987 update. Am Rev Respir Dis 1987; 136: 1285-1298.

3 American Thoracic Society. Single breath carbon monoxide diffusing capacity (transfer factor). Recommendations for a standard technique. Am Rev Respir Dis 1987; 136: 1299-1307.

4 American Thoracic Society. Lung function testing: selection of reference values and interpretative strategies. Am Rev Respir Dis 1991; 144: 1202-1218.

5 American Thoracic Society. Standardization of spirometry: 1994 update. Am J Respir Crit Care Med 1995; 152: 1107-1136.

6 American Thoracic Society. Single breath carbon monoxide diffusing capacity (transfer factor). Recommendations for a standard technique - 1995 update. Am J Respir Crit Care Med 1995; 152: 2185-2198.

7 Quanjer PH, ed. Standardized lung function testing. Report Working Party Standardization of Lung Function Tests, European Community for Coal and Steel. Bull Eur Physiopathol Respir 1983; 19: Suppl. 5, 1-95.

8 Quanjer PH, Tammeling GJ, Cotes JE, Pedersen OF, Peslin R, Yernault JC. Lung volumes and forced ventilatory flows. Report Working Party Standardization of Lung Function Tests, European Community for Steel and Coal. Official Statement of the European Respiratory Society. Eur Respir J 1993; 6: Suppl. 16, 5-40.

9 Cotes JE, Chinn DJ, Quanjer PH, Roca J, Yernault JC. Standardization of the measurement of transfer factor (diffusing capacity). Report Working Party Standardization of Lung Function Tests, European Community for Steel and Coal. Official Statement of the European Respiratory Society. Eur Respir J 1993; 6: Suppl. 16, 41-52.

10 Stocks J, Quanjer PH. Reference values for residual volume, functional residual capacity and total lung capacity. ATS Workshop on Lung Volume Measurements. Official Statement of The European Respiratory Society. Eur Respir J 1995; 8: 492-506.

11 Clausen JL, Coates AL, Quanjer PH. Measurement of lung volumes in humans: review and recommendations from an ATS/ERS workshop. Eur Respir J 1997; 10: 1205-1206.

12 Miller MR, Crapo R, Hankinson J, et al. General considerations for lung function testing. Eur Respir J 2005; 26: 153-161.

13 Miller MR, Hankinson J, Brusasco V, et al. Standardisation of spirometry. Eur Respir J 2005; (In press).

14 MacIntrye N, Crapo R, Hankinson J, et al. Standardisation of the single-breath determination of carbon monoxide uptake in the lung. Eur Respir J 2005; (In press).

15 Wanger J, Clausen JL, Coates A, et al. Standardisation of the measurement of lung volumes. Eur Respir J 2005; (In press).

16 NHLBI workshop consensus document on lung volumes. www.thoracic.org/adobe/lungvolume.pdf. Accessed: May 192005.

17 Pellegrino R, Viegi G, Enright $P$, et al. Interpretative strategies for lung function tests. Eur Respir J 2005; (In press).

18 Grasbeck R. The evolution of the reference value concept. Clin Chem Lab Med 2004; 42: 692-697. 